\title{
Perbedaan latihan passing berpasangan dengan perubahan tinggi net berat bola terhadap kemampuan passing bawah
}

\section{Difference in passing training couples with changes in heavy net ball weight on under passing ability}

\section{*1Pandu Kresnapati}

*1 Pendidikan Jasmani Kesehatan dan Rekreasi, Universitas PGRI Semarang, Semarang, Indonesia

Received: 06 June 2020; Accepted 28 July 2020; Published 05 August 2020

OPENOACCESS

\begin{tabular}{|c|c|}
\hline ABSTRAK & ABSTRACT \\
\hline $\begin{array}{l}\text { Tujuan dari penelitian ini adalah untuk mengetahui mana } \\
\text { yang lebih baik antara latihan passing bawah berpasangan } \\
\text { dengan perubahan tinggi net dan latihan passing bawah } \\
\text { berpasangan dengan perubahan berat bola. Metode yang } \\
\text { digunakan dalam penelitian ini adalah metode eksperimen. } \\
\text { Populasi penelitian ini adalah atlet bolavoli Klub Bina Taruna } \\
\text { Semarang yang berjumlah } 123 \text { atlet. Teknik pengambilan } \\
\text { sampel menggunakan purposive sampling yaitu pengambilan } \\
\text { sampel berdasarkan ciri, sifat, atau karakteristik tertentu. } \\
\text { Penelitian ini hanya meneliti sebagian dari populasi dengan } \\
\text { jumlah } 20 \text { orang atlet putera yang telah mengenal permainan } \\
\text { bolavoli khususnya passing bawah. Instrumen dalam } \\
\text { penelitian ini adalah alat tes passing bawah bolavoli Brady } \\
\text { Wall Volley Test. Data yang diperoleh dianalisis } \\
\text { menggunakan uji yang berbeda (uji-t). Berdasarkan hasil } \\
\text { penelitian dapat disimpulkan bahwa ada perbedaan yang } \\
\text { signifikan antara latihan passing bawah berpasangan dengan } \\
\text { perubahan tinggi net dan latihan passing bawah berpasangan } \\
\text { dengan perubahan berat bola. Pada kelompok eksperimen } \\
\text { yang mendapatkan latihan passing bawah berpasangan } \\
\text { dengan perubahan berat bola memiliki hasil yang lebih baik } \\
\text { bila dibandingkan dengan kelompok eksperimen yang } \\
\text { mendapatkan latihan passing bawah dengan perubahan } \\
\text { tinggi net. }\end{array}$ & $\begin{array}{l}\text { The purpose of this study is to find out which is better } \\
\text { between paired under passing exercises with changes in net } \\
\text { height and under paired passing exercises with changes in } \\
\text { ball weight. The method used in this research is the } \\
\text { experimental method. The population of the study was } 123 \\
\text { volleyball athletes Club Bina Taruna Semarang. The } \\
\text { sampling technique uses purposive sampling that is } \\
\text { sampling based on certain characteristics, characteristics, or } \\
\text { characteristics. This study only examined a portion of the } \\
\text { population with a total of } 20 \text { male athletes who were } \\
\text { familiar with volleyball, especially underpasses. The } \\
\text { instrument in this study was a Brady Wall Volley Test under } \\
\text { volleyball passing test. The data obtained were analyzed } \\
\text { using a different test (t-test). Based on the results of the } \\
\text { study it can be concluded that there is a significant } \\
\text { difference between under pairing passing exercises with } \\
\text { changes in net height and under pairing passing exercises } \\
\text { with changes in ball weight. In the experimental group who } \\
\text { got under-passing exercises in pairs with changes in ball } \\
\text { weight had better results when compared to the } \\
\text { experimental group who got under-passing exercises with } \\
\text { changes in netheight. }\end{array}$ \\
\hline Kata Kunci: Latihan; Berpasangan; Passing; Bolavoli & Keywords: Training; In pairs; Passing; Volleyball \\
\hline $\begin{array}{l}\text { *Corresponding Author } \\
\text { Email: pandukresnapati@upgris.ac.id }\end{array}$ & $\begin{array}{l}\text { Copyright @ } 2020 \\
\text { Edu Sportivo: Indonesian Journal of Physical Education }\end{array}$ \\
\hline
\end{tabular}

do

https://doi.org/10.25299/es:ijope.2020.vol1(1).5116

How To Cite: Krensnapti, P. (2020). Perbedaan latihan passing berpasangan dengan perubahan tinggi net berat bola terhadap kemampuan passing bawah. Edu Sportivo: Indonesian Journal of Physical Education, 1(1), 9-15. https://doi.org/10.25299/es:ijop e.2020.vol1(1).5116.

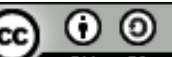

\section{PENDAHULUAN}

Sejalan dengan kemajuan ilmu dan teknologi, dalam bidang olahraga juga mengalami perkembangan yang pesat, yang lebih mencolok adalah adanya keterkaitan antara satu bidang pengetahuan dengan bidang lain. Bidang pengetahuan yang mengalami 
perkembangan yang baik adalah cabang olahraga, hal ini terbukti dari semakin majunya dalam hal teknik, taktik, dan perlengkapan atau sarana dan prasarana yang sangat menunjang kemajuan dan perkembangan olahraga. Hal ini bisa kita lihat dalam cabang olahraga bolavoli yang merupakan salah satu cabang olahraga yang memasyarakat di Indonesia (Miswar et al., 2018). Saat ini banyak cabang olahraga yang mengalami perkembangan yang sangat pesat. Orang tidak lagi berorientasi kepada kesenangan saja, melainkan lebih menuntut pada prestasi olahraga. Bolavoli termasuk cabang olahraga yang mengalami perkembangan semacam itu. Pada klub bolavoli era modern seharusnya sudah memulai pembinaan olahraga bolavoli yang sudah dilakukan secara bertahap mulai dari tahap pemula (multilateral) sampai tahap senior sebagai persiapan pembinaan ke arah olahraga (Ismoko \& Sukoco, 2013).

Permainan bolavoli merupakan cabang olahraga yang diminati masyarakat Indonesia, baik pria maupun wanita, dari lingkungan sekolah dasar hingga perguruan tinggi. Permainan bolavoli digemari oleh seluruh masyarakat Indonesia karena merupakan salah satu olahraga beregu yang dapat dimainkan bersama-sama untuk melatih kekompakan, disiplin, dan tanggungjawab. Permainan bolavoli tidak memerlukan tempat yang luas dan dapat dimainkan dalam segala jenis lapangan dengan permukaan rumput, kayu, pasir, dan berbagai macam lantai buatan. Peralatan permainan bolavoli mudah didapat dan tidak terlalu mahal (Fuaddi, 2018).

Dalam menghadapi persaingan kompetisi atau pertandingan, penguasaan teknik permainan sangat penting terutama dalam penguasaan teknik dasar permainan bolavoli. Karena untuk dapat melakukan permainan bolavoli maka perlu penguasaan teknik dasar yang meliputi servis, passing, smash, dan block (Gazali, 2016). Sedangkan menurut ( Suadnyana et al., 2014) Teknik dasar bolavoli ada empat macam yaitu: servis, passing, blocking, dan smash. Tanpa penguasaan teknik dasar tidak mungkin seseorang mencapai prestasi yang baik (Zainur \& Sulastio, 2019). Adapun syarat untuk melakukan teknik dasar permainan bolavoli adalah penguasaan teknik dasar yang baik dan benar. Seorang pemain bolavoli dalam pencapaian prestasi tidak hanya ditentukan oleh kondisi fisik saja akan tetapi lebih ditentukan oleh kemampuan teknik bermain.

Bolavoli adalah cabang olahraga yang banyak digemari oleh para remaja. Melalui kegiatan bolavoli, remaja memperoleh banyak manfaat, khususnya dalam hal pertumbuhan fisik, mental, dan social yang baik (Miswar et al., 2018). Permainan bolavoli terdapat satu elemen yang wajib harus dikuasai oleh seorang pemain bolavoli yaitu penguasaan kemampuan passing. Hal yang sama dikatakan oleh Vierra dan Fergusson (2004) yang mengatakan bahwa dalam permainan bolavoli yang sangat penting dipelajari salah satunya adalah passing. Kegunaan dari passing bawah bolavoli antara lain untuk menerima bola servis, menerima bola smash atau serangan dari lawan. Passing adalah mengoperkan bola kepada teman sendiri dalam satu regu dengan suatu teknik tertentu, sebagai langkah awal untuk menyusun pola serangan kepada regu lawan (Ahmadi, 2007). Passing sebagai penunjang sukses tidaknya permainan bolavoli baik pada saat melakukan serangan atau bertahan. Passing pada dasarya merupakan kunci dasar dalam suatu pemiainan bolavoli maka passing mutlak untuk di kuasai oleh semua pemain.

Permainan bolavoli pada dasarnya berpegang pada dua prinsip yaitu teknis dan psikis. Prinsip teknis dimaksudkan pemain memvolley bola dengan bagian badan pinggang ke atas, hilir mudik di udara lewat di atas net agar dapat menjatuhkan bola ke lapangan lawan secepatnya untuk mencari kemenangan secara sportif, sedangkan prinsip psikis adalah pemain bennain dengan senang dan kerjasama yang baik (PBVSI, 2005). Penguasaan teknik dasar dalam permainan bolavoli ini penting, mengingat ada 
beberapa hal sebagai berikut: (1) Hukuman terhadap pelanggaran permainan yang berhubungan dengan kesalahan dalam melakukan teknik, (2) Terpisahnya tempat antara regu satu dengan regu lain, sehingga tidak terjadi sentuhan badan dari pemain lawan maka pengawasan wasit terhadap kesalahan teknik ini lebih seksama, (3) Banyaknya unsur-unsur yang menyebabkan terjadinya kesalahan-kesalahan teknik, antara lain: membawa bola, mendorong bola, mengangkat bola, dan pukulan rangkap, (4) Permainan bolavoli adalah permainan cepat, artinya waktu untuk memainkan bola sangat terbatas, sehingga teknik-teknik kurang sempurna akan memungkinkan timbulnya kesalahan-kesalahan teknik yang lebih besar, (5) Gangguan taktik yang tinggi hanya dimungkinkan kalau penguasaan teknik dasar dan tinggi dalam bolavoli cukup sempurna.

Berdasarkan kemungkinan-kemungkinan yang dapat terjadi dalam permainan bolavoli seperti yang di atas, maka setiap pemain bolavoli harus selalu berusaha dan berlatih untuk meningkatkan dan menumbuh kembangkan pada kemampuankemampuan berupa teknik dasar permainan bolavoli. Mengkaji arti tentang pentingnya teknik-teknik dasar dalam permainan bolavoli, maka teknik dasar dalam permainan bolavoli mutlak harus dikuasai dengan baik dan sempuma oleh setiap pemain bolavoli. Latihan adalah suatu proses menyiapkan fisik dan mental anak latih secara sistematis untuk mencapai mutu prestasi optimal dengan diberikan beban yang teratur, terarah, meningkat, dan berulang-ulang waktunya (Chozin, 2014). Hal yang hampir sama juga dikemukakan oleh Sajoto (2010), latihan adalah suatu proses yang sistematis dari kegiatan berlatih atau bekerja secara berulang-ulang dengan setiap hari menambah beban latihan atau pekerjaan. Sedangkan menurut (Wiguna, 2017) latihan merupakan aktivitas olahraga yang sistematis dalam waktu yang lama, ditingkatkan secara progresif dan individual yang mengarah pada ciri-ciri fungsi fisiologis dan psikologis manusia untuk mencapai sasaran yang telah ditentukan.

\section{METODE PENELITIAN}

Metode yang digunakan dalam penelitian ini adalah metode eksperimen (Arikunto, 2016). Metode eksperimen adalah salah satu metode penelitian untuk menimbulkan suatu keadaan atau kejadian, kemudian diteliti bagaimana akibatnya. Penggunaan metode penelitian harus dapat mengarah pada tujuan penelitian, agar hasil yang dipeoleh sesuai dengan tujuan yang diharapkan. Populasi dalam penelitian ini adalah atlet putera Klub Bina Taruna Kota Semarang tahun 2020 yang berjumlah 123 orang pemain. Teknik pengambilan sampel dalam penelitian ini menggunakan teknik purposive sample, yaitu pengambilan sampel berdasarkan ciri, sifat, atau karakteristik tertentu. Besarnya sampel yang yang diambil berpedoman pada pendapat Miswar et al., (2018) yang menyatakan bahwa metode kuantitatif lebih menggambarkan masalah dalam bentuk keterangan hubungan antar variabel, hubungan sebab akibat (causal), hubungan perbandingan (comparative) atau hubungan asosiatif. Sifat hubungan yang diterangkan adalah linear. Masalah penelitian haruslah benar-benar masalah bukannya gejala (symptom). Sesuai dengan pendapat di atas penelitian ini meneliti sebagian dari populasi dengan jumlah 20 orang atlet putera yang telah mengenal permainan bolavoli khususnya passing bawah. Sampel yang digunakan dalam penelitian ini adalah pemain bolavoli putera Klub Bina Taruna Kota Semarang tahun 2020 yang berjumlah 20 orang. Instrumen dalam penelitian ini adalah alat tes untuk mengukur kemampuan passing bawah dalam permainan bolavoli. Setelah mendapatkan sampel maka diadakan tes awal passing bawah Brady Wall Volley Test dalam bukunya Suharno (1982). Analisis data yang diperoleh dianalisis menggunakan uji yang berbeda (uji-t). 


\section{HASIL PENELITIAN}

Berdasarkan hasil tes awal passing bawah yang telah dipasangkan dengan pola A-BB-A diperoleh data kemampuan awal dari masing-masing kelompok sebagai berikut:

Tabel 1. Skor Hasil Tes Awal Kemampuan Passing Bawah Kelompok Eksperimen 1 dan Kelompok Eksperimen 2

\begin{tabular}{ccccc}
\hline Kelompok & N & Rata-rata & SD & Tertinggi \\
\hline Eks 1 & 10 & 31,20 & 6,05 & 41 \\
\hline Eks 2 & 10 & 31,50 & 5,74 & 40 \\
\hline
\end{tabular}

Tabel 2. Skor Hasil Tes Akhir Kemampuan Passing Bawah Kelompok Eksperimen 1 dan Kelompok Eksperimen 2

\begin{tabular}{ccccc}
\hline Kelompok & N & Rata-rata & SD & Tertinggi \\
\hline Eks 1 & 10 & 34,70 & 5,19 & 42 \\
\hline Eks 2 & 10 & 36,50 & 5,19 & 44 \\
\hline
\end{tabular}

Tabel 3. Penghitungan dengan Uji-t Latihan Passing Bawah Berpasangan dengan Perubahan Tinggi Net dan Latihan Passing Bawah Berpasangan

\begin{tabular}{ccc|cccc}
\hline Kelompok & $\mathbf{N}$ & Rata & Sel & T hitung & T tabel & Ket \\
\hline Eks 1 & 10 & 34,70 & & \multirow{2}{*}{2,48} & \multirow{2}{*}{2,26} & Beda \\
\cline { 1 - 4 } Eks 2 & 10 & 36,50 & & & & \\
\hline
\end{tabular}

\section{Uji Hipotesis 1}

Berdasarkan uji beda pada tes akhir antara kelompok eksperimen 1 dan kelompok eksperimen 2 diperoleh 2,48 > 2,26, sehingga Hipotesis diterima. Hal ini menunjukan bahwa terdapat perbedaan latihan passing bawah dengan perubahan tinggi net dan dengan perubahan berat bola pada atlet putera dalam permainan bolavoli pada Klub Bina Taruna Kota Semarang tahun 2020. Kesimpulannya adalah bahwa hipotesis nihil yang menyatakan tidak ada perbedaan latihan passing bawah dengan perubahan tinggi net dan dengan perubahan berat bola pada atlet putera dalam permainan bolavoli pada Klub Bina Taruna Kota Semarang tahun 2020, ditolak. Sebaliknya, hipotesis alternatif yang menyatakan ada perbedaan latihan passing bawah dengan perubahan tinggi net dan dengan perubahan berat bola pada atlet putera dalam permainan bolavoli pada Klub Bina Taruna Kota Semarang tahun 2020. diterima.

\section{Uji Hipotesis 2}

Berdasarkan dengan hasil rata-rata, mean eks 1 3,4,7 dan mean eks 2,3,6,5 hipotesis diterima. Hal ini menunjukan hasil rata-rata kelompok eksperimen yang diberi latihan dengan perubahan berat bola lebih baik dibandingkan dengan hasil rata-rata kelompok eksperimen 1 yang diberi latihan dengan perubahan tinggi net terhadap ketepatan jump service atlet putera dalam permainan bolavoli pada Klub Bina Taruna Kota Semarang tahun 2020.

\section{PEMBAHASAN}

Tujuan dari penelitian ini untuk memberikan informasi terkait dengan perbedaan latihan bolavoli dengan latihan berpasangan dengan perubahan tinggi net serta berat bola terhadap kemampuan passing bawah dalam permainan bolavoli. Permainan bolavoli adalah olahraga yang dimainkan oleh dua regu diamana setiap regu berjumlah enam orang yang berada di dalam suatu lapangan yang memiliki ketentuan ukuran yang pisahkan oleh net (Suadnyana, et al., 2014). Passing bawah dalam bolavoli adalah 
dengan melakukan passing menggunakan kedua lengan dengan perkenaan pada bagian proksimal lengan passing bawah sangat efektif apabila dapat dengan perubahan berat bola awalnya mengalami kesulitan dalam melakukan passing bawah, karena belum terbiasa melakukan latihan passing dengan bola yang ukuranya lebih besar, hal tersebut membuat para atlet harus menguatkan tanganya supaya dapat menyesuaikan tekanan terhadap bola pada saat melakukan passing sehingga bola dapat melambung dan tepat pada sasaran atau pasanganya, akan tetapi setelah pertemuan berikutnya mereka (atlet kelompok eksperimen 2) sudah mulai terbiasa, bahkan setelah melakukan latihan passing bawah dengan bola berat kemudian melakukan passing dengan bolavoli yang berukuran normal, mereka merasakan bola tersebut terasa lebih ringan sehingga mereka dapat melakukan passing bawah lebih baik.

Dari fakta yang terjadi di lapangan maka dapat disimpulkan bahwa jika seorang atlet ingin dapat melakukan passing bawah dengan baik, maka atlet tersebut harus memiliki tangan yang kuat agar penguasaan terhadap bola lebih baik. Berdasarkan temuan yang diperoleh pada penelitian ini menunjukkan bahwa metode latihan passing bawah berpasangan menggunakan perubahan berat bola lebih baik dalam meningkatkan kemampuan passing bawah dibandingkan metode latihan passing bawah berpasangan menggunakan perubahan tinggi net. Hal ini diperkuat dari hasil penelitian Sari (2010) yang menyatakan adanya pengaruh secara signifikan antara pembelajaran inovatif dengan bola mini dan bola lunak dalam meningkatkan passing bawah bolavoli. Hal senada juga disampaikan oleh Fasikhatun (2012) yang menyatakan penerapan media bantu seperti bola plastik dapat meningkatkan passing bawah bolavoli pada siswa SD. Permainan yang menyenangkan yang inovatif bisa membuat atlet atau siswa menjadi bersemangat dalam proses peningkatan passing bawah dalam permainan bolavoli (Febriani \& Rifki, 2020).

\section{KESIMPULAN}

Berdasarkan hasil penelitian dengan menggunakan perhitungan statistik, maka dapat disimpulkan bahwa ada perbedaan yang signifikan antara latihan passing bawah berpasangan dengan perubahan tinggi net dan latihan passing bawah berpasangan dengan perubahan berat bola. Pada kelompok eksperimen 2 yang mendapatkan latihan passing bawah berpasangan dengan perubahan berat bola memiliki hasil yang lebih baik bila di bandingkan dengan kelompok eksperimen 1 yang mendapatkan latihan passing bawah dengan perubahan tinggi net. Hal ini dapat dipahami karena setelah melakukan latihan passing bawah menggunakan bola yang berat dan kemudian melakukan passing dengan bola berukuran normal para atlet merasakan bola yang berukuran normal lebih ringan dan mudah mengontrol laju bola sehingga dapat melakukan passing bawah dengan lebih baik.

\section{DAFTAR PUSTAKA}

Ahmadi, N. (2007). Panduan Olahraga Bolavoli. Era Pustaka Utama.

Arikunto, S. (2016). Prosedur Penelitian Pendekatan Praktek. Edisi Revisi VI. Rineka Cipta.

Chozin, N. (2014). Latihan Kekuatan dan Daya Tahan Otot. CV Pamularsih. 
Faozi, F., Sanusi, H., \& Listiandi, A. D. (2019). Pengaruh Model Pembelajaran Kooperatif Tipe Stad Terhadap Keterampilan Passing Bawah Dalam Permainan Bolavoli di SMA Islam Al-Fardiyatussa'adah Citepus Palabuhanratu. Physical Activity Journal,1(1), 51-60.

Fasikhatun, S. (2012). Meningkatkan Hasil Belajar Passing Bawah Bola Voli Mini dengan Menggunakan Modifikasi Bola Plastik Pada Siswa Kelas IV SD Negeri Kertasari 01 Kecamatan Suradadi Kabupaten Tegal Tahun Ajaran 2011/2012. Skripsi. Universitas Negeri Sebelas Maret.

Febriani, Y., \& Rifki, M. S. (2020). Pengaruh Metode Drills For Game-Like Situation Terhadap Kemampuan Passing Bawah Atlet Bolavoli. Jurnal Stamina, 3(6), 481-498.

Fuaddi. (2018). Kontribusi Power Otot Lengan Terhadap Kemampuan Servis Bawah Bolavoli Pada Extrakurikuler Putri SMP Negeri 6 Tambang. Journal Sport Area, 3(2), 148-156. https://doi.org/https://doi.org/10.25299/sportarea.2018.vol3(2).1903

Gazali, N. (2016). Kontribusi Kekuatan Otot Lengan Tehadap Kemampuan Servis Atas Atlet Bolavoli. Journal of Physical Education, Sport, Health and Recreations, 3(1), 16.

Ismoko, A. P., \& Sukoco, P. (2013). Pengaruh Metode Latihan Dan Koordinasi Terhadap Power Tungkai Atlet Bolavoli Junior Putri. Jurnal Keolahragaan, 1(1), 1-12. https://doi.org/10.21831/jk.v1i1.2339

Miswar, E., Amir, F., Chaliluddin, M. A., Affan, J. M., Studi, P., Sumberdaya, P., Kelautan, F., Kuala, S., \& Aceh, B. (2018). Jurnal Sains Riset / Volume VIII , Nomor 2 , Desember 201840 Jurnal Sains Riset / Volume VIII, Nomor 2 , Desember 2018 41. VIII, 40-45.

PBVSI. (2005). Peraturan Permainan Bolavoli. PP. PBVSI.

Raco, J. (2018). Metode Penelitian Kualitatif: Jenis, Karakteristik dan Keunggulannya. Jakarta: Grasindo.

Sajoto, M. (2010). Pembinaan Kondisi Fisik Olahraga. Ditjendikti.

Sari, V. D. M. (2010). Perbedaan Pengaruh Pembelajaran Inovatif Dengan Bola Mini dan Bola Lunak Terhadap Hasil Belajar Passing Bawah Bolavoli Pada Siswa Kelas Xi Smk Kristen Surakarta Tahun Pelajaran 2010/2011. Skripsi. Universitas Negeri Sebelas Maret.

Suadnyana, I. K., Kanca, I. N., Pasek, M. S., \& Ked, S. (2014). Implementasi Model Pembelajaran Kooperatif Tipe TGT Untuk Meningkatkan Aktivitas dan Hasil Belajar Passing Bolavoli. Jurnal Pendidikan Jasmani, Olahraga dan Kesehatan Undiksha, 2(1), 1-10.

Subroto, T., \& Yudiana, Y. (2010). Modul Permainan Bolavoli. Bandung: Universitas Pendidikan Indonesia. 
Suharno, H.P. (1982). Dasar-Dasar Permainan Bolavoli. Yogyakarta

Vierra, B. L., \& Fergusson, B. J. (2004). Bolavoli Tingkat Pemula.

Wiguna, I. B. (2017). Teori dan Aplikasi Latihan Kondisi Fisik. PT. Raja Grafindo Persada.

Zainur, \& Sulastio, A. (2019). Kontribusi Kekuatan Otot Tungkai dan Koordinasi MataKaki Terhadap Akurasi Tendangan ke Gawang. Journal Sport Area, 4(1), 278-284. 